\title{
La región sin límites. El trabajo como ethos e identidad en Primo Levi
}

\section{The Region without Limits. Work like Ethos and Identity in Primo Levi}

\author{
José Antonio Fernández López ${ }^{1}$ \\ Universidad de Murcia (España)
}

Recibido: 13-03-19

Aprobado: 22-11-19

\section{Resumen}

Al abordar el estudio de la obra de Primo Levi, encontramos, ligada al núcleo de referencias que tienen como fuente su experiencia como superviviente del Holocausto, una temática singular, concebida por el autor como ejemplo de respuesta de la razón humana frente a la barbarie. El trabajo creativo, el mundo de los oficios, recorre como profunda reivindicación moral toda la obra de Levi, siendo la línea de fuerza positiva más importante que puede hallarse en la misma. En el presente artículo vamos a abordar críticamente este fecundo ámbito de referencialidad, analizando su concepción, sus vinculaciones y sus límites.

Palabras-clave: Primo Levi, trabajo, oficios, Auschwitz, escritura.

\begin{abstract}
The study of the work of Primo Levi gives us a singular subject, linked to the nucleus of references that have as their source his experience as survivor of the Holocaust, conceived by the author as an example of the human reason's

\footnotetext{
${ }^{1}$ (joseantonio.fernandez13@um.es) Doctor en Filosofía por la Universidad de Murcia. Profesor del Departamento de Filosofía de la UM. Sus trabajos tienen como ámbito fundamental de estudio el pensamiento judío en sus distintas épocas, así como la reflexión sobre la problemática identitaria en la Contemporaneidad y su representación. Artículos han sido publicados por las revistas Anales del Seminario de Historia de la Filosofía, Daimon, Revista Española de Filosofía Medieval, Ilu, Isegoría o Yod. Autor, entre otras, de las obras Tiempo de Sefarad: la historia como consolación en el judaísmo español, A merced de la tormenta, Primo Levi: el oficio de vivir y de testimoniar.

ORCID: https://orcid.org/0000-0001-8569-1290.
} 
response against Barbarism. The creative work, the world of the trades, goes through the whole narrative of Levi as a deep moral vindication, being the most important force line that can be found in it.

Key-words: Primo Levi, Work, Trade, Auschwitz, Writing.

\section{Introducción}

Químico y escritor, científico y humanista, italiano y piamontés, judío de lejana ascendencia sefardita, superviviente del Holocausto, todos estos atributos definen la personalidad de Primo Levi, de quien se cumple el centenario de su nacimiento (Turín, 31 de julio de 1919-11 de abril de 1987). Su figura, más allá de tópicos y clichés, ejemplifica de forma privilegiada a un intelectual que reivindica la capacidad y la virtud de la racionalidad humana, a pesar y por encima de la ruina generada por sus propios sueños monstruosos. Su obra literaria y ensayística se halla al servicio de esta causa. En sus libros, la concisión, la sobriedad, la agudeza reflexiva y la emotividad poética son formas expresivas poseedoras de una profunda trascendencia: representan una victoria moral sobre la barbarie y dotan de sentido personal al sinsentido de sobrevivir a la inhumanidad de los campos. La violencia inútil y gratuita infligida sobre millones de inocentes, la locura organizativa puesta al servicio de la humillación y la eliminación de seres humanos, la existencia de amplísimas zonas de indefinición moral donde víctimas y verdugos se difuminan en un todo aberrante, la ausencia de Dios en la Babel degradante de Auschwitz, son cuestiones que significarán en nuestro autor un profundo reto de cara a su representación y a su desarrollo sistemático como reflexión filosófica. Conectada estrechamente con este ámbito de referencias que tienen como fuente la noche y la niebla caliginosa de la Shoá, una temática, si se quiere, diurna, luminosa y profundamente humanizadora será desarrollada por Primo Levi como respuesta moral frente a la barbarie. Topos clásico y fecundo, antítesis del pensar ontológico frente a la aniquilación del hombre y la subversión de su esencia, el trabajo creativo, el mundo de los oficios y la dimensión productiva del ser humano, traspasa como profunda reivindicación moral toda la obra de Levi. Contrapuntísticamente, allí donde el Holocausto es el centro explícito de toda representación posible, de modo amplio y prodigioso, allí donde se erige en centro de la narración, el trabajo es la línea de fuerza positiva más importante que recorre la obra de Levi. En el presente artículo, vamos a abordar este fecundo ámbito de referencia, repensando la concepción del trabajo del autor piamontés y analizando críticamente los límites de esta. 


\section{De natura humana}

Auschwitz como experiencia radical y negativa, como inversión del mundo, es en Primo Levi el punto de partida de una reflexión antropológica y ética que cuestiona los límites de una condición humana cuya diversidad de manifestaciones y de extremos el propio autor ha conocido y padecido. Íntimamente unidos por este propósito, Se questo è un uomo, La tregua, Il sistema periodico y La chiave a stella, conforman una sugerente summa de la condición humana, en la que basculan dialécticamente los ámbitos extremos que difuminan o violentan esta humanidad, frente a aquellos otros que la proyectan y objetivan, dotándola de sentido y valor. Una fuerza racionalizadora impulsa y atraviesa esta empresa, un espiritu de la narración que aspira a crear un orden nuevo, necesario tras el caos y la regresión. Confianza en el hombre, intuitiva y congénita, a la vez que avisada, a pesar y mas allá de la experiencia concentracionaria:

Creer en la razón quiere decir creer en la propia razón, no quiere decir que la razón gobierne al mundo o al hombre. Haber presenciado el naufragio de la razón, al nazismo y a nuestro fascismo, no debe llevar a una rendición [...] No hay permiso tampoco para la razón, no puede tomar vacaciones. Desconfío de todas las ausencias de la razón. Por eso considero saludables todos los oficios en los que se ejercita la razón y el mío es uno de ellos (Levi 1998a: 92).

Una muy notable singularidad se halla presente en la caracterización de esta razón que realiza Levi. Sin que ello sea afirmado explícitamente, un sesgo de ética aristotélica puede advertirse en la idea de racionalidad práctica que sostiene el autor. Dentro de un contexto general de apreciación ilustrada del valor del pensamiento crítico, Levi extiende los dominios de la razón más allá de la pura reflexión teorética o estrictamente científica. Más allá del to epistemonikón, las virtudes asociadas por Aristóteles al to logistikón, techné o arte y sabiduría práctica o phrónesis (cf. Eth. Nic. VI), son virtudes que para el autor de Si esto es un hombre expresan una serie de estados asociados a la vida activa y creativa del individuo, mediante los cuales el espíritu humano puede poseer la verdad. Una diversidad en la acción mediada por la racionalidad, que se expresa en forma de una variedad de oficios entre los cuales el más importante es vivir. Las dos ocupaciones fundamentales que marcarán su actividad vital, su trabajo como escritor y como químico, expresión ambas de esa mediación racional, se encuentran en Levi en estrecha conexión. Es esta una forma de sympatheia en la que en un caso la memoria y en otro los elementos químicos primigenios nutren una suerte de incesante creatividad. Es por ello por lo que crear posee una diversidad de significados, vinculados todos a una concepción artesanal de la acción humana: reelaborar y transformar la materia básica, destilar recuerdos o elementos, generar fórmulas maestras. 
Esta afirmación de la esencialidad constitutiva de la vida activa en el hombre puede hallarse en la obra de Levi ya desde sus inicios. En ese relato brumoso y con cierto aire de irrealidad, en el que la conciencia se va abriendo lentamente a la vida, que es "Historia de diez días", capítulo con el que concluye Si esto es un hombre, un deportado enfermo, aunque superviviente, hace memoria de la progresiva recuperación del sentimiento de su humanidad. Se erige en portavoz de unos compañeros de cautiverio que han padecido el acoso sistemático y perverso de un sistema cuya finalidad era reducirlos a una condición bestial. (Levi 1998a: 180). La historia de los días que transcurren desde el abandono por parte de los alemanes del Lager de Auschwitz hasta su liberación definitiva por parte de los rusos supone para Primo Levi, instalado en un barracón de infecciosos casi destrozado por los bombardeos, el inicio de una aventura apasionante de reconciliación con la vida. Si es cierto, como afirma George Steiner, que "no nos quedan más comienzos" (Steiner 2001: 11), y que la historia de la barbarie ha hecho impactar su obscura condición en la gramática ( $c f . i d .17)$, no resulta difícil de entender la mirada que Levi realiza hacia el pasado fundante y originario para comprender el hecho excepcional de la vuelta a la vida. En aquel momento, afirma, "el recuerdo de los salvamentos bíblicos en las adversidades extremas pasó como un viento por todos los ánimos" (Levi 1995a: 165). En una nueva creación sellada a partir de un pacto secular con la existencia, Primo Levi, "como un Robinson en el infierno", le arranca a una isla maldita y despiadada lo que le hace falta para vivir ( $c f$. Roth 2003: 17).

Los últimos días en el campo están también asociados, en la memoria del superviviente, a un objeto singular y de marcado carácter simbólico. Remolques, de Roger Vercel (1943), es el primer libro que cae en manos de Primo Levi tras un prolongado ayuno en el que "además de hambre de pan, sentí hambre de papel impreso" (Levi 2004: 179). La historia narrada allí no puede ser una metáfora más lograda. El mar, símbolo intemporal de la muerte que gravita sobre la existencia humana, es surcado por el Cyclone, un remolcador de altura a los mandos del capitán Renaud. Este barco de salvamento en mares siempre embravecidos es el último nexo con la civilización. En medio del azul oscuro que amenaza con engullirlo todo cual Leviatán, la actividad humana puede ser salvación. Levi, un hombre decimonónico que aparenta no haber perdido la ingenuidad, cree con bríos renovados en la fuerza creadora del ser humano, en los productos positivos de su razón e ingenio, en la capacidad rehabilitadora de su trabajo.

Con Auschwitz siempre como referencia última, directa o indirecta, como estímulo y exigencia intelectual, Primo Levi va a desarrollar una personal reflexión asistemática sobre el sentido de la identidad humana. En ella se erige como eje fundamental la dignificación de la vida mediante el trabajo creativo. 
Recuerdo aquilatado de sus lecciones escolares en el Gimnasio-Liceo D'Azeglio (cf. Cases 1987: 144), la valoración existencial del trabajo que realiza Levi se plantea en términos clásicos: la potencialidad de una materia reacia y hostil, una hylé que no quiere plegarse al hombre y que, por ello, estimula su razón, llevando a la plenitud en la proyección activa de sí mismo el sentido de su vida y del mundo. Giuseppe Grassano ha advertido cómo la confluencia del científico y el escritor en Levi parece subrayar un ideario en el que la lucha, el esfuerzo del hombre, son el fundamento del dominio de sí y de la realidad (cf. 1981: 126). Ahora bien, sería un error confundir a Levi con un escritor naturalista o un cientificista desaforado. Ni el más tecnológico de sus relatos de ciencia-ficción deja de ser un cuento moral disfrazado. No podemos sustraernos a la impresión de estar ante un humanista clásico que busca la identificación filosófica de la condición humana negada por Auschwitz, mediante el esfuerzo y la ejercitación, mediante la confrontación de la vida con el propio hombre y la naturaleza. Tanto en los relatos de Historias naturales como en los de Defecto de forma, el escritor se lanza a una sutil y mediada forma de testimoniar. Ideando situaciones y personajes en los que se entremezcla la química, la biología, la etnología y la filosofía, propone una visión del mundo traspasada por las manifestaciones y concreciones de un error siempre achacable al hombre. Ni la naturaleza hostil, ni la humanidad que ha creado el Lager, se hallan en estado de primigenia bienaventuranza, afirma Levi. Dado que el Edén devino en filial del infierno en la tierra, tan sólo al ser humano le es posible, merced al uso de su racionalidad, transformar el caos posterior al origen en un nuevo y provisional comienzo. La experiencia de sentir el cosmos como algo caótico, como un enorme poder oculto y opresivo, deviene liberación en el marco de una creatividad que es antídoto frente a ese poder desbordante y turbador. El sentido del orden atómico, molecular, de los elementos químicos dispuestos taxonómicamente en el sistema periódico, se trasfunden naturalmente en el discurso de la representación artística (cf. Cases 1987: 23). En "Disfilaxis", una peculiar historia natural perteneciente a la colección Lilit y otros relatos, a medio camino entre la ética cósmica y la ficción científica, da cuenta Levi de esta obligación esencial, de este nuevo imperativo categórico: "Y era extraño y maravilloso que la naturaleza trastornada hubiera reencontrado su coherencia. Junto a la fecundidad entre especies diversas había nacido el deseo, a veces grotesco y absurdo, a veces imposible, de ser feliz" (Levi 1998b: 129).

Vinculado a este descubrimiento, el trabajo se presenta como un modo existencial de dar coherencia al kháos, de domesticar y humanizar su poder (cf. Tesio 1991: 225-248). Y por ello, concebirá su labor original de químico, desempeñada durante treinta y cinco años, como la posibilidad de entrar en contacto con la materia para comprender el mundo que nos rodea, una actividad que, ya incluso de niño, le parecía como "la llave principal para abrir los 
secretos del cielo y de la tierra" (Levi 1996: 130). En El sistema periódico, obra que puede leerse como la autobiografía de un químico, se hace patente de modo excepcional esta relación, que evidencia la comprensión de la identidad humana tal como la concibe Levi. En esta obra original, la materia, tomada en sentido literal, adopta unas connotaciones especiales de ligereza, pero también de comportamiento esquivo, que evocan la lucha y la relación del poeta con las palabras. Los elementos químicos que componen la materia, presentes en la naturaleza con diversas modalidades, representan una verdad metafórica, perceptible para el autor.

Que la nobleza del Hombre, adquirida tras cien siglos de tentativas y errores, consistía en hacerse dueño de la materia, y que yo me había matriculado en Química porque me quería mantener fiel a esa nobleza. Que dominar la materia es comprenderla, y comprender la materia es preciso para comprender el universo y conocernos a nosotros mismos, y que, por lo tanto, el Sistema Periódico de Mendeléiev era un poema, más elevado y solemne que todos los poemas que aprendíamos en clase (Levi 2004: 49).

\section{Arbeit macht frei}

La búsqueda de un territorio intelectual en el que poder conciliar verdad y vida es, en la obra de Levi, una exigencia epistemológica y moral frente al agujero negro de Auschwitz. La importancia dada por Levi al tema del trabajo, la obsesiva presencia de esta problemática en la mayor parte de su obra ha sido interpretada como un compromiso ético personal por devolver al trabajo su significado humano, "redimiendo a la palabra Arbeit del ridículo cinismo con que la desfiguraron los responsables de Auschwitz" (Roth 2003: 15). Levi, que acepta este análisis, reconoce que tras su liberación el trabajo de químico y el trabajo de escritor, sus "dos modalidades de trabajo", desempeñaron un papel fundamental en su vida. Sólo una actividad apuntada hacia un fin, en la equivalencia "trabajo y problema solucionado" (id.16), dota de sentido y dignifica la vida del hombre. En Auschwitz, el trabajo y el escaso ocio, ambos alienantes, eran fuentes de inagotables padecimientos, de atrofia. El Lager no fue pensado originariamente como un lugar de trabajo útil, tan sólo como un campo de trabajos forzados. Estas, en palabras de David Rousset, "sombrías ciudadelas solitarias de expiación" (2004: 66), fueron levantados para la reeducación de presos políticos. No será más que por la concurrencia de casualidades históricas, producto del desarrollo desfavorable de la guerra, por lo que también llegaron a ser "empresas de trabajos públicos" (id. 67). La construcción de Auschwitz responderá a esta necesidad, convirtiéndose en el reflejo más completo del hibridismo enloquecido que caracterizó a la 
ideología nacionalsocialista y a su perversa estructuración social: exterminio mediante la explotación (Levi 1996: 104). La mano de obra esclava, necesaria para la industria alemana, era prestada por las $S S$ sólo el tiempo justo y en condiciones que pudieran degradar física y moralmente al recluso con rapidez; una diarquía en la que la fábrica dominaba el día con rigor e inhumanidad, mientras que las $S S$ eran los señores de la noche, administradores de la vida y de la muerte de los Häftlinge en extremas condiciones de violencia ambiental. Se ha puesto de relieve cómo en Auschwitz - donde se hallaban recluidos judíos y no judíos- fueron trazadas unas líneas de acción específicas sobre el trabajo de los reclusos judíos. Estas directrices, procedentes de fuentes que competían entre sí, terminaban generando unos resultados que, si bien eran perjudiciales desde la lógica del rendimiento empresarial, eran enormemente productivos, por el contrario, desde la lógica monstruosa del exterminio ( $c f$. Goldhagen 2003: 363).

Primo Levi vivió por mor de su condición y de un sino azaroso este aberrante experimento sociopatológico. Tras su deportación en un tren de mercancías a Auschwitz desde el campo italiano de tránsito de Carpi-Fossoli (en el Valle del Po, cerca de Módena), será derivado al campo anexo de Monowitz o Auschwitz III. Allí trabajará en brigadas (kommando) dedicadas a tareas extremadamente duras a la intemperie, hasta ser incorporado como auxiliar químico al laboratorio de la fábrica de caucho sintético Buna. Primero, apilando pesados materiales en sótanos húmedos e insalubres, y después, durante un breve período, como auxiliar en el laboratorio de la fábrica, desempeñando tareas inútiles semanas antes de la liberación del campo. Junto a una forma de providencia invertida que pareciera premiar la locura frente al sentido común y la moral, en Auschwitz también imperaba la lógica de la razón empresarial. Tanto el campo como la fábrica pertenecían en realidad al emporio químico alemán I. G. Farbenindustrie, dividido tras la derrota del nazismo en las empresas Hoechst, Bayer y Basf. Buna-Monowitz era pues un campo de concentración privado de cuya seguridad se encargaban las SS, las cuales, a su vez, eran las "propietarias" de la mano de obra esclava de los Hälftlinge, por cuyo uso recibían una compensación del empleador (cf. Borkin 1978: 190-210). En 1960 Primo Levi recibirá, tres años después de haber presentado una demanda junto a su compañero Lello Perugia, una compensación de I. G. Farbenindustrie de dos mil quinientos marcos (cf. Anissimov 2001: 376-379). Una indemnización por un año de trabajo esclavo en Auschwitz, en una fábrica de la que nunca llegó a salir ni un solo gramo de goma.

En este punto, es necesario recordar cuál fue la visión del trabajo en la Alemania nacionalsocialista. En pleno esfuerzo de guerra, un país sin mano de obra y obligado a captarla por todos los medios, obviaba sin complejos cualquier referencia a una ética laboral para esta clase de trabajadores. Al igual que en 
Auschwitz-Monowitz, en miles de instalaciones industriales y de obra pública la inagotable fuente de mano de obra esclava participaba de una inversión de las relaciones productivas que alcanzaba el paroxismo. Esta praxis, dependiente del proceso de aceleración histórica y de inversión de valores de la guerra total, en cualquier caso, no era ajena a la propia formulación teórica que el fascismo había desarrolla desde sus inicios. En la concepción fascista y revolucionaria del trabajo que defendió el nacionalsocialismo, el trabajador es el sujeto de una modificación histórica definitiva, el portador de un tipo humano nuevo, un estilo de ser y estar en el mundo cuyo objeto es, nada menos, que la superficie entera de la tierra. Con la maestría y la ambivalencia características en él, Ernst Jünger vislumbró y teorizó esta figura en la Alemania de 1932, dentro de la idea de Estado total que se avecinaba. Su reflexión posee una innegable concomitancia con el tono y el fondo del Heidegger de La autoafirmación de la Universidad Alemana, donde la revolución nacionalsocialista es vista como el despliegue del mundo espiritual de un pueblo, la afirmación de un pueblo que se alza y plantea la pregunta inquietante del ser: ¿por qué hay algo y no, más bien nada? Ese mundo, que garantiza al pueblo su supuesta grandeza, "no es una superestructura cultural como tampoco un arsenal de conocimientos y valores utilizables, sino que es el poder que más profundamente conserva las fuerzas de su raza y de su tierra" (Heidegger 1989: 209). En esta línea, el trabajo, tal como lo entiende Jünger, no tiene nada que ver con el sentido moral expresado en la concepción positiva judeocristiana, tampoco con la interpretación histórico-económica y de lucha de clases formulada por el marxismo, no pudiendo subsumirse, finalmente, en el marco de una compleja actividad tecnológica, por más que esta última aporte medios necesarios para su comprensión. El trabajo no es actividad, ni está sujeto a valoración moral, sino que es la materialización de un ser nuevo y especial del hombre, no sometido a ningún tipo de ley, una realidad que "no conoce nada que se le oponga fuera de sí, ninguna antítesis [...] no hay ninguna situación que no pueda ser concebida como trabajo" (Jünger 2003: 90). La obsolescencia del ideal de progreso decimonónico y la quiebra de los valores de la Modernidad son el punto desde donde arranca esta identificación del trabajo y el ser, una nueva identidad que garantiza a sus sujetos históricos seguridad y estabilidad. Frente a ellas, ya no es posible ninguna contaminación, ninguna destrucción espiritual, ninguna oposición ideológica. La lógica reaccionaria del planteamiento de Jünger se retroalimenta con una exigencia nihilista de tintes mesiánicos: la búsqueda sin descanso de ámbitos "donde concebir la destrucción no como clausura o terminación, sino como una anticipación, ver que el futuro logra intervenir en el pasado y en el presente" (id.92). ¿Quiénes son los sujetos de esta transformación revolucionaria? La respuesta de Jünger pone aún más al descubierto la profunda esencia pequeñoburguesa de este o orden nuevo: funcionarios, soldados, agricultores, un municipio, todo un pueblo, a los que se enfrentan "otros que creen ser trabajadores sin que quepa ya calificarlos como tales" (id.). El nuevo estilo, las nuevas fuerzas, tan potentes y efectivas como la pólvora negra, preparan una unidad dramática cuya aparición "cabe vislumbrar detrás de las ruinas de la cultura y bajo la máscara mortal de la civilización" (id. 94). 
Cuando la locura cesó, intelectuales como Jünger quedaron perplejos ante la enorme cantidad de ruinas que el fallido advenimiento del hombre había provocado. Ni hubo destino, ni el nuevo pueblo alemán de trabajadores patentizó el ser. La cantidad de pólvora aplicada al derribo fue mal calculada y las ruinas resultaron inabarcables. Primo Levi será testigo de este irracionalismo deshumanizador y víctima de la fuerza de su perversión, que no banalidad.

\section{La región sin límites}

Inspirado en la mitología judía -en una relectura de la Leyenda de Praga-, el relato "El siervo", incluido en la colección Defecto de forma, es una representación de esta experiencia destructiva. En este cuento, un golem creado a partir de materia inanimada, siervo del hombre, pero no de Dios, invierte el orden del trabajo y de la naturaleza provocando la destrucción y la tristeza (cf. Levi 1989: 177-186). Para humanizar el mundo y devolver a la actividad humana la virtud perdida en la catástrofe de los campos, es necesaria, cree Levi, una mirada renovada que indague en el devenir de la historia. Sin perder de vista las ruinas y los caminos errados, el objetivo es explorar históricamente cómo el hombre ha desplegado su actividad imaginativa y transformadora, subvirtiendo el caos, la nada, lo hostil. Todo ello, en la búsqueda de un residuo o esencia: la ingenua y efectiva fuerza transformadora que emerge en el placer por la obra creada.

Con esta intencionalidad surge La llave estrella, uno de los grandes textos de Primo Levi, cuya publicación le convirtió en un escritor ampliamente reconocido. De La chiave a stella Claude Levi-Strauss afirmó que permitía que Primo Levi fuese "admitido en las filas de los antropólogos", tal como explica el propio escritor (Levi 1998a: 67). Tino Faussone, el protagonista que cuenta y escucha en una lograda simbiosis con el narrador, es el portador de un valor universal: el trabajo como una afirmación de lo todo lo que de positivo encarna el ser humano. Trasunto, en el sentido de la sentencia clásica de Claudio Apio, del hombre capaz de controlar y de transformar su entorno ("Homo faber suae quisque fortunae"), Faussone es la encarnación de la creatividad que se despliega con sentido y que lleva a término la tarea emprendida. En este sentido, el trabajo, expresión de racionalidad práctica, es una victoria moral cuya eticidad explora la superación dialéctica de dos concreciones extremas y alienantes del mismo: la punitiva del Lager y la explotadora del capitalismo. En la concepción conradiana de la vida que asume Levi -representada como vector y fuerza en el meridiano de la "estatura del hombre" de La búsqueda de las raices (cf. Levi 2004: 41)- el ingenio creativo se halla al servicio de la humanización y la transformación positiva del mundo, donde son esenciales 
las acciones donde se ejerce la responsabilidad con miras a un objetivo. Ello no es óbice, como reconoce el propio autor, para afirmar que, triste y de forma evidente, el mundo del trabajo no es idílico y que no todo el mundo puede realizarse en el trabajo, que existe la explotación y el subempleo ( $c f$. Levi 1998a: 93).

Faussone no es un técnico ni un ejecutivo, es un obrero especializado que recorre el mundo con otros compañeros realizando instalaciones metálicas para la industria. Su peregrinar le permite encontrarse con personajes de toda condición, a los cuales se siente unido por el lenguaje universal del trabajo bien hecho. Como artificio literario, La llave estrella no sólo opera como correa de transmisión de los ideales que encarna este original universalismo, sino que también transforma la propia actividad de narrar en la representación de esa forma de trabajo. Como si la tarea de un ajustador-montador se tratara, el material en bruto de la narración el escritor "lo trabaja, lo rectifica, lo esmerila, le quita las rebabas, lo alabea un poco para sacar una historia" (Levi 2001: 7). La obra se gesta como idea tras una estancia de Levi en Togliattigrado, en la antigua Unión Soviética, donde permanece una larga temporada ocupándose de una resina para los frenos de los automóviles Fiat, y es un homenaje a los técnicos de todas las nacionalidades con los que convive en las instalaciones de la empresa. Para el autor, al margen de consideraciones sobre el modelo político y económico-productivo que lo inspira, el descomunal complejo industrial en el que se encuentra representa la antítesis del babel desquiciado de Buna-Monowitz: en Togliattigrado, las barreras lingüísticas no eran obstáculo para el desarrollo de un sentimiento de comunidad basado en la idea del trabajo positivo (Levi 1998a: 67).

Puede resultar sorprendente el que La llave estrella, ambientada en la antigua URSS, no acompañe su exaltación eudaimónica del trabajo creativo, antítesis de la experiencia inhumana y degradante de Auschwitz, con alguna clase de referencia a la concepción marxista del trabajo y a su concreción en el modelo soviético; y, sobre todo, resulta más que evidente su silencio en torno a los aspectos más negativos del desarrollo histórico de esta forma de economía planificada en lo que directamente a la idea de trabajo se refiere, simbolizados por el Gulag. Un halo de indisimulada simpatía se desprende en aquellos pasajes de sus obras donde Levi describe el alma rusa, ya sea desde la naturaleza de sus paisajes o desde la idiosincrasia y organización de su sociedad. La Unión Soviética como entidad económico-política es subsumida por el escritor dentro de un constructo lírico-afectivo, el caos primigenio de la Rusia por la que deambula un joven superviviente del Holocausto que trata de retornar a su tierra. La tregua es, en este sentido, la narración épica de un regreso a casa desde los impenetrables bosques y pantanos de Bielorrusia, una aventura traspasada por un halo de libertad, de retorno a la vida y de jovial 
anarquía de alguien que ha sobrevivido al orden inmisericorde del Lager. A través de bosques "tan salvajes que parecen eternos" (Levi 1997: 110), Levi entrevé una concomitancia entre su feracidad y el alma del pueblo ruso. Una y otra vez describe con simpatía el desorden y desorganización de unos hombres y mujeres salvajes, tiernos y anárquicos, cuya indolencia contrapone a la violencia y supuesta eficacia teutónica. La constatación de esta disimilitud psicosocial está en sintonía o es expresión, si se quiere, de la asimetría hermenéutica que, como elemento de una comprensión teórica del fenómeno del totalitarismo, es compartida por Levi con otros escritores supervivientes de Auschwitz como Imre Kertész o Jean Améry, si bien, no con la profundidad y radicalidad de estos últimos (cf. Améry 2001: 93-95; Kertész 1999: 58-60). Preguntado en muchas ocasiones por su silencio en torno al Gulag, Levi se decidirá a esbozar una respuesta en el "Apéndice de 1976" para la edición escolar de Si esto es un hombre, donde remarcará, más allá de "las obvias semejanzas" las que él considera "diferencias sustanciales". Estas diferencias, más que proporcionar una comprensión del fenómeno de los campos soviéticos, sirven para ahondar en el carácter incomparable del universo concentracionario nazi. Abundando en una idea expresada en repetidas ocasiones por Thomas Mann y teorizada, posteriormente por Jean Améry, "es fácil imaginar un socialismo sin campos: en muchas partes del mundo se ha conseguido. No es imaginable, en cambio, un nazismo sin Lager" (Levi 1995a: 199).

Otros marcos de hermenéutica comparativa se activan con la lectura de La llave estrella. Pensamos que la concepción del trabajo y de la existencia que tiene Faussone se halla en las antípodas de aquella encarnada por el homo faber arquetípico de la literatura contemporánea, el ingeniero Walter Faber, protagonista de la novela homónima del suizo Max Frisch. Este técnico de mentalidad pragmática concibe su trabajo como "el ardid técnico para organizar el mundo de tal manera que no lo tengamos que vivir", la necesaria conversión de la creación en algo útil dado que el hombre "no la soporta como compañera" (Frisch 1991: 159). Faber, ingeniero de turbinas, que al igual que Faussone recorre el mundo desarrollando su competencia profesional, comprueba en primera persona y en circunstancias extremas las limitaciones de la tecnología y de la organización racional de las actividades humanas; una experiencia radical a partir de cual su vida terminará deslizándose hacia la incondicionalidad de lo casual e irracional. A diferencia de Faber, el protagonista de La llave estrella sirve de altavoz a un ideario que se sitúa más allá de lo dicotómico y que es, por supuesto, inasequible a lo irracional -un irracional que, en cualquier caso, en Frisch no es sino apertura al mundo de los sentimientos en detrimento de la esclavitud de los esquemas racionales-. En pasajes donde se entrelaza la calidez de lo humano con lo inquietante y hostil, Levi despliega una suerte de mitología moderna donde fusiona lo natural y lo tecnológico, narración etiológica que 
afirman la vida y cubren con un velo de misterio la muerte. Así, podemos leer cómo "una vez terminado el trabajo aquella torre extractora parecía un bosque", un trabajo exigente y necesitado de la más estricta precisión, que, sin embargo, durante su realización era experimentado por los operarios como el juego de unos niños "cuando hacen castillos en la playa con la arena y el agua". Esa torre, un derryck de dimensiones colosales, levantado por Faussone y sus colegas, alzada con esmero y pericia, al ser una creación humana no está exenta del concurso del error. Es entonces, por mor de su inevitable e intrínseca limitación, cuando "la instalación sufre... como una gran bestia a la que le falta el resuello"; una columna enferma que "empezaba a parecerse a una de esas bestias que existían en los tiempos primitivos y que luego murieron todas, quién sabe por qué" (Levi 2001: 18, 20, 25).

El habilidoso operario y artesano Zajar Pávlovich, uno de los protagonistas de la excepcional novela de Andréi Platónov Chevengur (1927), comparte con Faussone la idea de que el hombre se supera a sí mismo en el trabajo bien hecho. Pero a diferencia de este último, el primero desprecia a una naturaleza en cuyo seno ni el troquel único ni la maestría del trabajo humano se manifiestan per se; aunque viva, a ojos del que la transforma se encuentra inane. Por el contrario, la idea de una hybris resultante de la interacción de la naturaleza con la actividad humana, se formula en Levi como una forma de admiración filosófica ante la inmensidad de los retos que esa naturaleza propicia, a la vez que como fascinación por el trabajo artesanal y los oficios antiguos. En el capítulo "Batir la hojalata" de La llave estrella, el narrador responde a la afirmación de Faussone, basada en su experiencia profesional, de que "cuando se bate el cobre se endurece", con una oda donde la relación primigenia de los elementos químicos se funde en sugerente alquimia con la estructura moral del hombre:

\footnotetext{
Sí lo sabía, aunque nunca hubiera batido la hojalata, tenía con el cobre una vieja relación, atravesada de amor y de odio, de batallas silenciosas y encarnizadas, de entusiasmos y fatigas, de victorias y derrotas, y grávida de un conocimiento cada vez más agudo [...] Conocía en efecto la condescendencia femínea del cobre, metal de los espejos, metal de Venus; conocía su esplendor cálido y su sabor malsano, el blando verde-celeste de sus óxidos y el azul vítreo de sus sales. Conocía con mis propias manos, el endurecimiento del cobre, y cuando se lo dije a Faussone nos sentimos un poco parientes. Si se lo maltrata, es decir, se lo golpea, pliega, comprime, hace como nosotros: sus cristales crecen y se torna duro, crudo, hostil (Levi 2001: 74-75).
}

La región sin límites de la actividad laboral, impermeable frente a ideologías, descréditos y renuencias, el mundo de los oficios tan antiguo como el mundo, es un atavismo consubstancial a la identidad cultural del ser humano que Levi erige como símbolo de redención secularizado. Contrapunto y barrera 
frente a la barbarie humana, a excepción de esos breves instantes de gozo que el destino nos depara por azar "el amor por el propio trabajo (que, por desgracia, es privilegio de pocos) constituye la mejor aproximación concreta a la felicidad en la tierra" (id. 77). Conocemos, afirma el autor, la retórica vacía y ampulosa que exalta el trabajo en ceremonias oficiales, ya sea en Estados totalitarios o democráticos, con entrega de medallas y premios. También, esa retórica negativa vulgar que lo denigra y lo considera algo vil ( $c f$. Levi 1998a: 93). En cualquier caso, no abunda Levi en un análisis de los elementos alienantes asociados al trabajo, cuya existencia, por otro lado, el autor reconoce; no se siente concernido a teorizar su visión de las relaciones y estructuras de producción en el sistema industrial capitalista. Lo que sí es evidente, es que postula su concepción del trabajo como fuente de creatividad y de felicidad de modo no antagónico al trabajo fabril contemporáneo. Creemos que, en este punto, el elemento determinante son sus vivencias personales positivas como técnico y gerente de la fábrica de barnices Siva de Settimo Torinese, su lugar de trabajo durante casi toda su vida. Leemos en La llave estrella:

Se puede y se debe combatir para que el fruto del trabajo quede entre las manos de quien lo origina, y para que el trabajo como tal no sea un puro penar; pero el amor, respectivamente el odio, hacia la obra son un dato interno, originario, que depende mucho de la historia del individuo, y menos de lo que se cree de las estructuras productivas en cuyo mareo se desarrolla el trabajo (Levi 2001: 78).

Pero hay otras formas de aproximación crítica al tema del trabajo de las cuales Levi no se hace eco, y resulta sorprendente dada su contemporaneidad con la obra del autor. Realizada desde una revisión de los postulados marxistas, esta visión ha problematizado hasta el extremo el trabajo como fundamento ontológico de la existencia. Pensadores del operaismo italiano como Antonio Negri, Franco Berardi o Maurizio Lazzarato, o enmarcados en su posterior desarrollo, como en el caso del propio Negri, merced a su encuentro con los teóricos posestructuralistas franceses. Aunque sea brevemente, a sabiendas de que una presentación justa de la misma desborda el marco de este de este ensayo, debemos mencionar esta ontología negativa del trabajo. Así, para Negri, el trabajo ha dejado de ser un valor y se ha transformado en un problema. Desprovisto de su racionalidad de la medida marxista, el trabajo llega a ser el mal, la pérdida absoluta de finalidad y la exaltación de una neutralidad y trascendencia técnica aparentes ( $c f$. Negri 1982: 11-35). El trabajo, desequilibrado ontológicamente, se convierte en un evento trágico e insensato, el dominio de la heteronomía absoluta. Ninguna instancia permite justificar el mundo, "salvo el descubrimiento de un dolor tan profundo e insoluble que llegue a ser, en una inversión extrema, la causa y fin negativos del mundo. El mundo es el resultado del trabajo negativo, la definición de una teología 
negativa" (Negri 2003: 38-39). Una reconstrucción del horizonte del valor de trabajo, no obstante, se abre paso en esta lectura como forma de liberación, como nuevo comienzo. "Ruptura del horizonte de insignificancia axiológica y de indiferencia vital" del trabajo, la discontinuidad creativa que supera las formas de organización tradicional del trabajo, desde la "creación colectiva de un mundo nuevo" (id. 44-45), es el territorio en el que la tragedia del trabajo esclavo ilumina el carácter absoluto de la potencia creativa humana.

Giuseppe Varchetta ha destacado cómo la complejidad afectiva y estructural del trabajo contemporáneo organizado ha encontrado en las páginas de Primo Levi un relato que se aleja de estas lecturas críticas sobre la esencia del trabajo y su configuración estructural (2010: 59). Existe un énfasis en señalar la separación de los elementos de una vida humana subsumida en la idea de la posesión, en la necesidad de llegar apresuradamente a unos objetivos concretos. Una irreconciliabilidad intrínseca y perjudicial ha sido establecida en el trabajo fabril entre la vida del hombre en su variedad diaria, en su creatividad, y la linealidad causal-temporal que ofrecen la organización del trabajo. Así, desde la perspectiva del operaismo, por ejemplo, la organización se ha tornado incapaz de definir las identidades de todos los sujetos. Levi, por el contrario, se sitúa entre aquellos que entienden la organización fabril como un teatro de los sujetos posibles, como un ámbito que da la bienvenida a la creatividad de los sujetos, acoge su creatividad y les proporciona los medios para descubrir sus objetivos (id. 61). Las páginas de La llave estrella son la constatación de este cuestionamiento de la interpretación negativa de la organización del trabajo. Subvirtiendo la contraposición entre libertad y trabajo, ha recuperado al trabajador cualificado como individuo susceptible de protagonizar una historia ejemplar.

Existe, en cualquier caso, una zona gris, de contornos mal definidos, un ámbito de indeterminación ética y gnoseológica cuya fuente primaria es esa misma historia del individuo (Levi 1995b: 35), que pudo hacer dudar a Levi de la posibilidad de alcanzar en esta vida la felicidad amando y haciendo bien el propio trabajo. Recurso heurístico de un valor incalculable, esa historia también puede ser una maraña de fracturas profundas. La dimensión moral, testimonial y simbólica que el escritor Levi erigió como la más personal de las exigencias vitales, estuvo marcada irremediablemente por un halo de trágica negatividad. Una suerte de pecado existencial original, vinculado a su condición de víctima superviviente, acompañará a este hombre optimista e ilustrado, basculando dialécticamente sobre su propio ideal liberador-creativo de la existencia productiva como forma de redención. Hannah Arendt ha aportado una interpretación de esta fragilidad de lo vital, de esta dicotomía genuinamente humana en su estudio de la acción en La condición humana (cf. Arendt 2005: 207-219). Si el mundo puede conservarse o destruirse, 
individual como históricamente, la vita activa, la acción, es el ámbito en el que se representan los hombres, constituyendo el teatro del mundo y el sentido último de la libertad humana. Frente al punto de vista de los hechos naturales y de los procesos automáticos que parecen determinar la marcha del mundo, la acción significa tomar la iniciativa, poner un inicio, un comienzo. Si nueva acción y todo nuevo principio "cae en una trama ya existente", debido a esta actualidad de lo ya existente y al carácter de gran trama de interrelaciones de donde se subsume toda acción, "la acción casi nunca logra su propósito". Siendo también cierto que en este modo de ser condicionado y, a la vez, imprevisible, la acción siempre produce un relato, unas historias contadas dentro de una historia general que carece de autor, "porque no está fabricada" (Arendt 1995: 105). Esta ausencia confiere a los asuntos humanos un halo de fragilidad, de inevitabilidad y de falta de fiabilidad. Frente a la incapacidad de deshacer lo ya hecho, para Arendt, lo irreversible e irremediable puede hallar una peculiar redención en forma de una doble mirada existencial: al pasado, como perdón que deshace lo ya hecho; al futuro, como promesa mantenida capaz de lograr la identidad y continuidad que producen la personas con una vida susceptible de ser narrada ( $c f . i d$. 106-107).

\section{Los trabajos de Tiresias}

La llave estrella marcó en 1978 un punto de inflexión en la vida de Primo Levi, significando el final de su actividad profesional como químico y el inicio de su actividad a tiempo completo como narrador de historias, su dedicación exclusiva a la escritura. Al artesano dedicado durante más de treinta años a hilvanar largas cadenas de moléculas, el oficio de escribir se le representa como otra forma de artesanía. Como un tejedor, el escritor transforma un ámbito también corpuscular y atómico, las palabras e ideas, en historias:

Historias mías mientras me quedaran en la faltriquera, y luego historias de otros, robadas, rapiñadas, sacadas por la fuerza u obtenidas gratis; o también historias de todo el mundo y de nadie, historias descabelladas, pintadas en un velo, siempre y cuando tuvieran algún sentido para mí o pudieran regalar al lector algún momento de estupor o de risa (Levi 2001: 139).

La obra literaria de Levi, compleja y peculiar, nace del laboratorio de un alquimista en el que los elementos químicos adoptan la forma de un nuevo sistema periódico de lo humano. En su particular atanor se entremezclan en orden desigual la propia idiosincrasia del autor, el mundo azaroso de sus circunstancias personales, vicisitudes históricas, aspectos técnicos y formales de sus actividades laborales, una actitud de asombro ante el mundo y, por 
último, la búsqueda incesante de una respuesta al hombre que se confronta con el caos y sus potencias. Marcada en su esencia por la intencionalidad testimonial, aun afrontando empresas literarias de suerte y temática diversa, alejadas algunas de ellas de la temática concentracionaria, la actividad como escritor de Levi no podrá desvincularse del origen de todo. Mecanismo psicológico y exigencia moral, la reserva anamnética actuará en el escritor como canalizador y depósito del caudal de recuerdos del Lager, así como de instancia mnemagógica generadora de historias. La vida como escritor dedicado en cuerpo y alma al oficio de narrar será para Levi una experiencia azarosa, una forma de existencia artística limitada por la emergencia recurrente de los recuerdos y por la imposibilidad de zafarse de las exigencias de su condición de memorialista. Marcada por la incomprensión de los críticos, obtuvo, a pesar de todo, la compensación afectiva del calor del público y el éxito de ventas. En su personal combinación de sencillez formal, laconismo expresivo y veracidad moral, tal vez descanse este éxito. Humanista ilustrado, irónico y con un profundo sentido de la responsabilidad ética, judío secularizado maravillado tanto por el eterno preguntar del Talmud como por la esperanza implícita en el conocimiento científico del cosmos, Primo Levi escribe con un estilo cuyo modelo "no es ni Petrarca ni Goethe, sino el informe de fin de semana, el que se redacta en la fábrica o en el laboratorio, que tiene que ser claro y conciso, poco condescendiente con lo que se llama bella literatura" (Levi 1998a: 38).

En la autoindagación que realiza Primo Levi de su progresiva conversión en escritor, una singular alegoría se abre paso como forma de hermenéutica. Concibe el autor su existencia como el extraño hibridismo de un centauro, la vida de un hombre de varias almas, fundidas en una inmensa, gran y única búsqueda. Escritor profesional, sin embargo, la cualidad anamnética de su identidad será irreductible: nunca dejará de ser un ex deportado y nunca dejará de testimoniar sobre la barbarie. Vinculada con esta irreductibilidad, otra evidencia la hace aún más patente: a pesar de su afán por abordar como narrador con libertad cualquier temática, incluso en sus colecciones de relatos científicos más distantes en apariencia del núcleo de sus experiencias concentracionarias, puede rastrearse la presencia solapada y sorda del Holocausto. En la autoconciencia de esta limitación, la afinidad que encuentra en la comprensión de su vida con el adivino ciego de la ciudad de Tebas, Tiresias, no sólo es metafórica. Al igual que el vidente mitológico, el cual, tras topar en el bosque con un nido de serpientes, iniciará una increíble experiencia de mutación identitaria, también él conoció las disputas entre dioses y la raíz de la que brota el mal más radical. Ese encuentro, afirma, transmutó su condición, confiriéndole el "extraño poder de la palabra" (Levi 2001: 50).

La problemática dualidad identitaria del hombre de diversos tipos de acción encuentra resolución en la obra creada. Y, no obstante, esta instancia 
liberadora genera una unidad que es intrínsecamente insatisfactoria. El proceso artesanal de la creación literaria, la región sin límites, expresa una dialéctica existencial donde el escritor siente que se enfrenta a la paradoja de la alienación y la extrañeza de aquello concebido. A diferencia del químico industrial, para el que, más allá de la inevitable enajenación, el producto de su trabajo posee la substancia de lo tangible, para el escritor superviviente, la creación literaria, traspasada por una necesidad anamnética que bordea el abismo de lo psicológico, deviene objeto inaprehensible. Concernido de lo irremediable de esta irreductibilidad, un halo de serena austeridad parece expresar la aceptación de este sino. Podemos interpretarla como una forma de senequismo, de disposición estoica a la que una mentalidad racionalista y científica se pliega, frente a evidencias existenciales de las cuales ni el más convencido de los optimistas se puede zafar. Sometidos al abismo del recuerdo, el esmero y la fruición del artesano se hacen fuertes en la forma. Así, la claridad y la concisión expresan una empresa racional que ilumina hasta el relato más críptico o fabulístico, una unidad de coherencia que se opone al "escribir oscuro y atormentado" (cf. Levi 1998b: 190-195).

La preocupada búsqueda de un estilo propio y coherente con el fondo de sus experiencias culminará en Levi con la publicación en La Stampa (11-XII1976) de un artículo titulado "De la escritura oscura". Este hecho, además, será el desencadenante de una agria polémica que le enfrentará a Giorgio Manganelli. Levi defiende que el escritor tiene que revelar una visión del mundo amplia y organizada que permita establecer al lector una conexión mínima con su universo referencial. Manganelli, con el lenguaje exaltado propio de los convulsos setenta, tachará esta concepción, en un artículo que aparece en el Corriere della Sera unas semanas después (3-I-1977), de retrógrada, un para la cual "irracional" es siempre sinónimo de negativo o inaccesible, dando por hecho que Levi se suma al carro de todos los reaccionarios enemigos de la búsqueda de nuevas formas de expresión. Años después, Levi recogerá en L'altrui mestiere una colección de cincuenta artículos aparecidos en La Stampa, entre los que se encuentra el citado "De la escritura oscura" (1985). La compilación, que lleva como subtítulo Notas para una redefinición de la cultura, muestra a un Levi muy poco reaccionario, más bien, la imagen que subyace en estos textos es la de un humanista impenitente, un ilustrado que añora la integralidad y el enciclopedismo de la cultura en la Modernidad.

Levi no se sustraerá a ninguna de las demandas implícitas al pensar sobre su experiencia concentracionaria. Es en este sentido como debe entenderse su racionalismo ilustrado: el deseo de comprender hasta el fondo. Cuando escribe no busca simplificar lo vivido. Comprender es, al contrario, hallar el núcleo esencial de las experiencias que sólo son aprehensibles desde la reducción fenomenológica y la eliminación de lo superfluo de los 
acontecimientos. Y nada más eficaz para ese propósito que el relato breve, que Levi transforma en herramienta maestra a lo largo de toda su obra. Estamos de acuerdo con Marco Belpoliti cuando afirma que Primo Levi es, ante todo, un escritor de cuentos (1998: 129). De hecho, esta preponderancia del cuento, la importancia del relato breve en la obra de Levi es evidente hasta en su gran obra memorialística. Al leer Si esto es un hombre tenemos la impresión de hallarnos en un antiguo cinematógrafo. Al igual que en la técnica narrativa del primer cine, los distintos episodios y escenas se suceden mediados por la apertura y cierre del objetivo de la cámara. La descripción de la vida de un deportado en Auschwitz, enmarcada por los capítulos inicial y final, se nos presenta como una sucesión de breves estampas que no corresponden con la cronología de los acontecimientos, sino, básicamente, con secuencias temáticas que expresan el punto de vista del narrador. En general, los relatos de Levi, a diferencia, por ejemplo, de sus poemas, surgirán de forma continua y constante ( $c f$. Grassano 1981: 134-136). En ellos encuentra el autor un punto de inmediatez para la comunicación, en un formato que permite que las inquietudes existenciales, las preocupaciones éticas o el mero deseo del divertimento, puedan canalizarse con eficacia. Por eso, la mayoría de sus obras narrativas se componen de textos breves, pensados y escritos en distintos momentos, a los que se recurre a posteriori para conformar un proyecto que los unifica tras una lenta y reflexiva concepción. Esta vocación por el escrito breve respondería al deseo de abarcar tantas posibilidades expresivas como fuera posible, en la búsqueda siempre de un vehículo apropiado para sus preocupaciones morales ( $c f$. Belpoliti 1998: 131).

Ya hemos destacado, al abordar la concepción de Levi del ser humano como un ser creativo y productivo, la existencia de un ámbito de indeterminación ética y gnoseológica cuya fuente primaria es la propia historia del individuo. Una suerte de pecado existencial original, vinculado a su condición de víctima superviviente, pende cual amenaza sobre esa idea de que la vida productiva es una forma de redención. En la interpretación que de la experiencia creativa realiza Levi y en los vínculos de ésta con su propia existencia, esta relación es concebida como un juego propiciatorio. A través de él, emergen a la luz vivencias profundas y radicales que son el material base de la creación. Pero, en este proceso, trascendiendo el círculo vital del creador, estas experiencias adquieren un significado propio que las independiza de su propio autor. Más allá de la convergencia en el medio lingüístico y de su formalización, operado por un proceso universal que afecta a todo creador, el mundo de la vida del escritor, una vez convertido en obra literaria, se enajena y aleja, alterando y reubicando identitariamente a su creador. De esta alienación consubstancial a la vida de escritor da cuenta Levi en su relato "La fugitiva". Toda creación humana es una obra cuya materialización pone en fuga su materia primigenia y 
última; esencial a toda obra creada es su resistencia ser identificada con su autor (cf. Levi 1998b: 159-165).

Esta intuición universal es captada de forma excepcional por Italo Svevo en La historia del buen viejo y la bella muchacha. Coincidencia curiosa, Svevo - cuyo verdadero nombre era Ettore Schmitz-, judío triestino, dirigió una fábrica de pinturas y barnices. Entre su gama de productos, esta fábrica suministraba pintura anticorrosiva a la marina imperial austrohúngara. En los últimos años de su vida el viejo protagonista de la historia de Svevo se convierte en escritor. Conforme escribe, poco a poco, va despojándose de su vida y de la memoria de sus experiencias. En su afán por indagar mediante la escritura en su propio yo, termina alcanzando, al fin, el profundo origen de todo. Y esta búsqueda fenomenológica de la raíz última de la que brota la obligación de escribir, deviene demoledora certeza: no hay respuesta al preguntar incesante, no hay ningún puente fiable que permita conectar al yo con la obligación de escribir. Una fábula sobre la vida y la escritura, sobre una Europa senil y decadente, pero, sobre todo, una fábula sobre el creador y el mundo de la vida como relación obligada e imposibilidad esencial.

\section{Referencias bibliográficas:}

Améry, Jean (2001). Más allá de la culpa y la expiación. Valencia: Pre-Textos. Anissimov, Myriam (2001). Primo Levi o la tragedia de un optimista. Madrid: Complutense.

Arendt, Hannah (1995). De la historia a la acción. Barcelona: Paidós.

- (2005). La condición humana. Barcelona: Paidós.

Belpoliti, Marco (1998). Primo Levi. Milán: Mondadori.

Borkin, Joseph (1978). The Crime and Punishment of IG-Farben. Nueva York:

The Free Press.

Cases, Cesare (1987). Patrie lettere. Turín: Einaudi.

Ferrero, Ernesto, ed. (1997). Primo Levi: un'antologia della critica. Turín: Einaudi.

Frisch, Max (1991). Homo Faber. Barcelona: Seix Barral.

Goldhagen, Daniel J. (2003). Los verdugos voluntarios de Hitler. Madrid: Taurus.

Grassano, Giuseppe (1981). Primo Levi. Florencia: La Nuova Italia.

Heidegger, Martin. "La autoafirmación de la Universidad Alemana”. Arethé 1. 2 (1989): 205-214.

Jünger, Ernst (2003). El trabajador. Dominio y figura. Barcelona: Tusquets. Kertész, Imre (1999). Un instante de silencio en el paredón. Barcelona: Herder. Levi, Primo (1988). Historias naturales. Madrid: Alianza Editorial. 
—. (1989). Defecto de forma. Madrid: Alianza Editorial.

-. (1995a). Si esto es un hombre. Barcelona: Muchnik.

- (1995b). Los hundidos y los salvados. Barcelona: Muchnik.

- (1996). En diálogo con Ferdinando Camon. Madrid: Anaya \& Mario Muchnik.

—. (1997). La tregua. Barcelona: Muchnik.

-. (1998a). Entrevistas y conversaciones. Ed. M. Belpoliti. Barcelona: Península.

-. (1998b). Lilit y otros relatos. Barcelona: Muchnik.

-. (2004a). El sistema periódico. Barcelona: El Aleph.

-. (2004b). La búsqueda de las raíces. Barcelona: El Aleph.

-. (2018). L'altrui mestiere. Turín: Einaudi.

Negri, Antonio (1982). Macchina tempo: rompicapi, liberazioni, costituzioni. Milán: Feltrinelli.

- (2003). Job: la fuerza del esclavo. Barcelona: Paidós.

Roth, Philip (2003). El oficio: un escritor, sus colegas y sus obras. Barcelona: Seix Barral.

Rousset, David (2004). El universo concentracionario. Barcelona: Anthropos. Steiner, George (2001). Gramáticas de la creación. Madrid: Siruela.

Tesio, Giovanni (1991). Piemonte letterario dell'Otto-Novecento: da Giovanni Faldella a Primo Levi. Roma: Bulzoni.

Varchetta, Giuseppe (2010). Ascoltando Primo Levi. Milán: Guerini e Associati. 